International Journal of Biomedicine | June 2021 - Volume 11, Issue Suppl_1: Abstracts from the Third Russian International Conference "Cryo-electron microscopy 2021: achievements and prospects"

\author{
POSTER ABSTRACT PRESENTATIONS
}

SESSION TITLE: STRUCTURE OF VIRUSES AND CHAPERONINS

DOI: 10.21103/JJBM.11.Suppl_1.P47

\title{
Abstract P-47: Analysis of Phosphorus Distribution in Giant Bacteriophage Capsid by Electron Energy Loss Spectroscopy
}

\author{
$\underline{\text { Tatiana Trifonova }^{1}}$, Andrey Moiseenko $^{1,2}$, Olga Shaburova ${ }^{3}$, Maria \\ Bourkaltseva $^{3}$, Viktor Krylov ${ }^{3}$, Olga Sokolova ${ }^{1}$ \\ ${ }^{1}$ Lomonosov Moscow State University, Moscow, Russia \\ ${ }^{2}$ Semenov Institute of Chemical Physics, Russian Academy of Sciences, \\ Moscow, Russia \\ ${ }^{3}$ I.I. Mechnikov Research Institute of Vaccines and Sera, Moscow, Russia
}

Background: We have recently developed a method to visualize the distribution of DNA in the cytoplasm of bacteria by analytical electron microscopy (EM), using the Phosphorus signal (dsDNA contains two phosphate groups per each nucleotide pair), that was detected and mapped onto the image of the cell (Danilova et al, 2020; Loiko et al, 2020). Here we applied this technique to study much smaller objects - the DNA packing inside bacteriophage heads. We studied phiEL, giant phiKZ-like bacteriophage of the Myoviridae family that infects Pseudomonas aeruginosa (Krylov et al, 2003). We have earlier demonstrated that this phage contains an 'inner body' inside its capsid, which is responsible for the specific DNA packing (Sokolova et al, 2014).

Methods: The phage propagation was performed as described before (Sokolova et al, 2014). A 3 ul sample of purified bacteriophage phiEL was applied to the glow-discharged carbon-coated copper grid and stained with freshly prepared ammonium Molybdate 2\% aquatic solution for $30 \mathrm{sec}$. Grids were loaded into Gatan cooling holder and the temperature of the specimen was kept at $-180^{\circ} \mathrm{C}$.

EELS spectra and phosphorus elemental maps were obtained on JEOL2100 microscope, operating at $200 \mathrm{kV}$ with the Gatan GIF Quantum ER spectrometer in STEM mode. Pixel size was set to $15-20 \mathrm{~nm}$. STEM drift correction was applied after each 40-50 pixels. Each spectrum was obtained at a $6.0 \mathrm{mrad}$ collection angle, $0.25 \mathrm{eV}$ dispersion, and $132 \mathrm{eV}$ energy shift. The spectra from different pixels were aligned to carbon K-edge. 
Results: Phosphorus mapping inside and outside the bacteriophage capsid was performed (Fig. 1). Outside the capsid, the phosphorus signal was practically absent, which corresponds to the presence of DNA only inside the capsid. The distribution of phosphorus inside the capsid was uneven: the rectangular area in the middle of the capsid contained a weak signal, while a more intense signal was detected on the periphery. This can be explained by the presence of an 'inner body' inside (Fig. 1C).

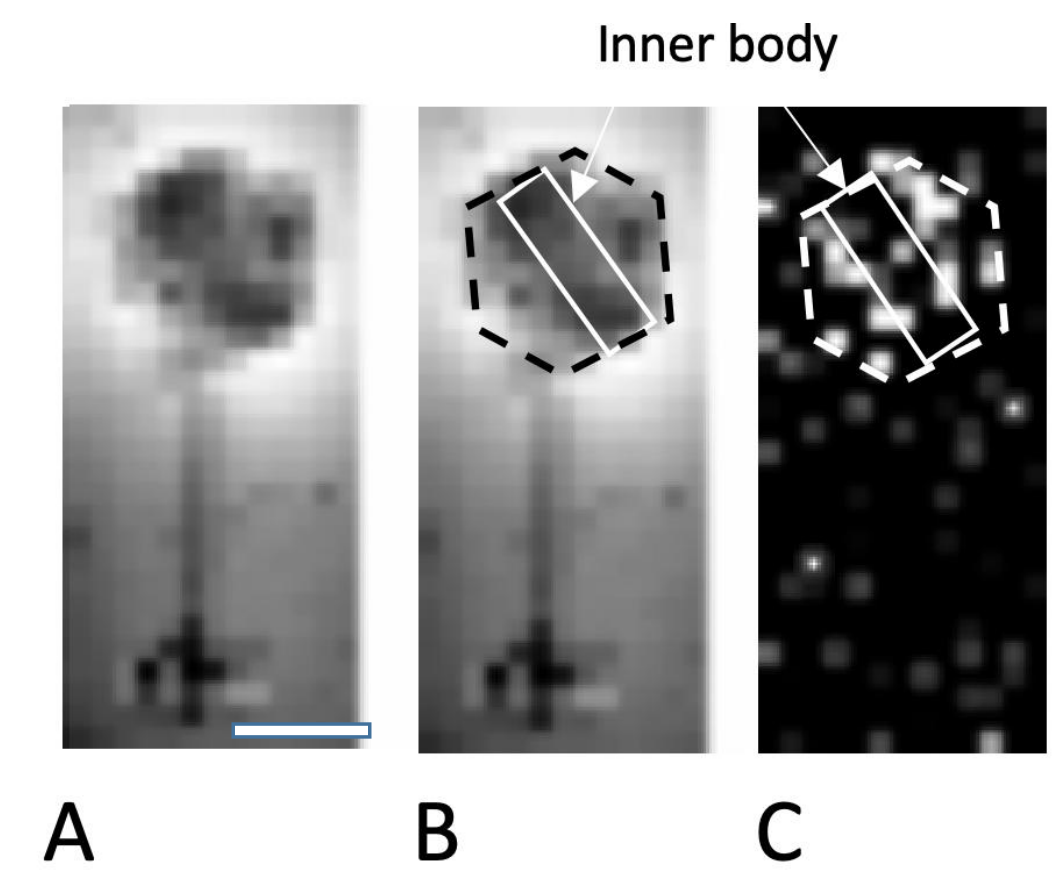

Fig. 1. Mapping of Phosphorus in bacteriophage EL. (A) HAADF image of phage EL. Bar - $100 \mathrm{~nm}$; (B) The inner body (white rectangle, marked by the arrow) appears darker against the background of the DNA in the capsid (black dashes). (C) Map of phosphorus distribution. The brightness of the pixels reflects phosphorus signal level.

Conclusion: Thus, our results justify the possibility of using the analytical EM technique to study the distribution of DNA by mapping Phosphorus in biological nano-objects at relatively low content of the element.

Key Words: analytical EM • EELS $\bullet$ Pseudomonas aeruginosa $\bullet$ phage phiEL - DNA packing

This work was supported by the Russian Science Foundation (Grant No. 2144-07002 to O.S.S.).

*Corresponding author: Tatyana Trifonova. E-mail: trf@ya.ru

International Journal of Biomedicine. 2021;11 Suppl 1: S33.

doi: 10.21103/IJBM.11.Suppl_1.P47

(C)2021 International Medical Research and Development Corporation 